\begin{tabular}{|c|c|}
\hline Regaido & $\begin{array}{l}\text { Revista Legado de Arquitectura y Diseño } \\
\text { ISSN: } 2007-3615 \\
\text { ISSN: } 2448-749 X \\
\text { legado_fad@yahoo.com.mx } \\
\text { Universidad Autónoma del Estado de México }\end{array}$ \\
\hline
\end{tabular}

\title{
REDEFINIENDO EL CONCEPTO DE NECESIDAD PARA UN CONTEXTO DE DISEÑO MÁS SUSTENTABLE Y/O SOCIALMENTE RESPONSABLE
}

Victoria-Uribe, Ricardo; García-Albarrán, Marco Antonio

REDEFINIENDO EL CONCEPTO DE NECESIDAD PARA UN CONTEXTO DE DISEÑO MÁS SUSTENTABLE Y/ O SOCIALMENTE RESPONSABLE

Revista Legado de Arquitectura y Diseño, vol. 2019, núm. 26, 2019

Universidad Autónoma del Estado de México, México

Disponible en: http://www.redalyc.org/articulo.oa?id=477961406006

Esta obra está bajo una Licencia Creative Commons Atribución-NoComercial-SinDerivar 4.0 Internacional. 
REDEFINIENDO EL CONCEPTO

DE NECESIDAD PARA UN CONTEXTO DE DISEÑO MÁS SUSTENTABLE Y/O SOCIALMENTE RESPONSABLE

\author{
REDEFINING THE CONCEPT OF NEED, FOR A \\ MORE SUSTAINABLE DESING CONTEXT AND/OR \\ SOCIALLY RESPONSIBLE \\ Ricardo Victoria-Uribe sustentabledi@gmail.com \\ Universidad Autónoma del Estado de México, México \\ Marco Antonio García-Albarrán \\ marco.garcia.albarran@gmail.com \\ Universidad Autónoma del Estado de México, México
} Revista Legado de Arquitectura y Diseño,
vol. 2019, núm. 26, 2019

Universidad Autónoma del Estado de México, México

Recepción: 22 Abril 2019

Aprobación: 02 Junio 2019

Redalyc: http://www.redalyc.org/ articulo.oa?id=477961406006
Resumen: Uno de los objetivos del diseño es satisfacer las necesidades de las personas, éstas tienen dos orígenes: reales y creadas. Las segundas, son explotadas para generar modelos de consumismo, enraizadas en la necesidad de la gente de llenar vacíos emocionales (por ejemplo, de la autoestima). Estos están derivados de tendencias y de contexto sociocultural. Como resultado, se manifiesta un consumismo desbordado por parte del individuo, lo cual no es sustentable y rara vez socialmente responsable. En buena medida, esto es ocasionado por la forma en que se ha interpretado el concepto de necesidad dentro de la profesión del diseño.

El propósito es redefinir cómo el diseñador debe entender el concepto de necesidad, de manera que sus propuestas de diseño tengan un cariz más sustentable y/o socialmente responsable. Esto, a través de una revisión teórica del modelo clásico de necesidad de Maslow, el modelo más reciente de Max-Neef y el papel que las emociones juegan en cómo el usuario valora sus necesidades y los bienes que las satisfacen. Así, se puede combinar ambas visiones para poder proponer un modelo de evaluación que indique si un objeto determinado atiende esta reinterpretación de necesidad.

Palabras clave: consumismo, diseño, necesidades, responsabilidad social, sustentabilidad.

Abstract: One of the aims of design is to satisfy people's necessities. Usually, these have two origins: Actual and fabricated. The latter-the fabricated ones-are exploited to generate consumerism models, they root for the people's desire of filling up emotional void (e.g. selfesteem). These are derived from trends and the socio-cultural context. As result, this is reflected as overconsumption by the individual, which is not sustainable and rarely socially responsible. In good measure, this is the result of how the concept of 'need' is used within Design.

The aim of this paper is to redefine how the designer should understand the concept of 'need', in order to make their design proposals more sustainable and/or socially responsible. This, through a review of the literatura of the classic model of needs by Maslow, the more recent model by Max-Neef, as well as the role emotions play in the way a person values its needs. That way, is possible to combine both visions to propose an evaluation model that can elucidate if an object fits this reinterpretation of need.

Keywords: consumerism, design, needs, social responsibility, sustainability. 


\section{INTRODUCCIÓN}

Para asegurar su supervivencia y desarrollo, todo ser vivo requiere satisfacer sus necesidades. Actualmente, la satisfacción de las necesidades en nuestra especie no sólo se resuelve, sino que también se manifiesta a través de la generación de nuevos productos, servicios y experiencias. El sistema económico actual, especialmente en países occidentales, ha sido responsable de fomentar la obtención constante de bienes materiales para mantenerse funcionando. Si bien, hay bienes materiales que satisfacen necesidades presentes (ej: techo, ropa y comida), la forma en que estos, y otros bienes que no cumplen una función más allá de generar una percepción particular sobre quien los adquiere, son presentados para su adquisición apelando a fomentar un 'estilo de vida', en lugar de satisfacer una necesidad. Lo que deriva en el consumismo, que tiene severas implicaciones para la sustentabilidad del planeta.

Es posible entender el consumismo como la acumulación y solicitud innecesaria de bienes y servicios no considerados como esenciales (Leonard, 2010). Lo que promueve una falsa sensación del individuo de necesitar estatus, riqueza y prestigio. Como consecuencia, genera impactos ambientales y sociales considerables, ya que para satisfacer esas necesidades en particular, se consumen recursos que generan desperdicio.

\section{El consumismo excesivo}

\section{GENERA UNA FUERTE CARGA AMBIENTAL Y SOCIAL}

\section{ENEL ENTORNO DEL INDIWDUO.}

El consumismo excesivo genera una fuerte carga ambiental y social en el entorno del individuo. Ambientalmente, porque utiliza y sobreexplota recursos naturales. Socialmente, porque genera desbalances económicos en el individuo que repercuten en su núcleo familiar. El consumismo inicia su desarrollo a lo largo del siglo XX como consecuencia directa del sistema capitalista y de la mercadotecnia asociada ; esta última tiene como objetivo crear nuevas necesidades en el consumidor de modo de aumentar las ventas de los productos para hacer crecer la economía.

Uno de los objetivos más importantes del diseño en la actualidad es el satisfacer necesidades demandadas por los consumidores. Sin embargo, Bhamra y Lofthouse (2007) consideran que cuestionar si un producto es en realidad necesario, debe ser una preocupación elemental de cualquier diseñador responsable, que aspire a hacer diseño sustentable. Esto parecería ser contrario al objetivo actual del diseño. Es menester replantear cómo se entienden las necesidades, cómo son afectadas por factores (tales como las emociones ), así como el rol que juegan dentro del diseño y la sustentabilidad. 


\section{EL PAPEL DE LAS NECESIDADES EN LA SUSTENTABILIDAD}

En términos de la sustentabilidad, las necesidades juegan un papel importante, tanto, que forman parte de la misma definición. De acuerdo con el Reporte Brundtland (1987), la sustentabilidad o el desarrollo sustentable se define como "el desarrollo que soluciona las necesidades presentes sin comprometer las necesidades de generaciones futuras para resolver las propias". Para que algo -un producto, un servicio o una política- sea considerada sustentable, debe resolver una necesidad, dentro de un marco de mesura en el consumo de recursos para hacerlo, y teniendo en cuenta consideraciones ambientales, sociales, económicas y éticas.

Dado que la sustentabilidad se puede considerar una filosofía de hacer y pensar las cosas, ésta permea en todo. Esto incluye al diseño. De manera integral, Bharma y Lofthouse (2007) consideran que el diseño que aspire a ser sustentable debe considerar problemáticas sociales como el uso, el impacto en las comunidades, donde los respectivos recursos naturales son extraídos, así como el diseño para la satisfacción de las necesidades humanas que serán cubiertas.

\section{EL PAPEL DE LAS NECESIDADES EN EL DISEÑO}

Uno de los objetivos del diseño es satisfacer las necesidades de las personas. Derivado de los trabajos de Victor Papanek (1985) en los que buscaba motivar a los diseñadores a distinguir entre necesidades y deseos, es factible clasificar la forma en que se entienden las necesidades dentro del diseño en dos vertientes:

- Son reales, necesarias para el bienestar físico y/o mental de la persona.

- Creadas, para vender un producto nuevo que puede o no ser útil, pero que para ser vendido apela a ciertas necesidades subjetivas, emocionales del consumidor, que el producto no resuelve, pero da la apariencia de hacerlo.

Estas últimas -las creadas- son explotadas para generar modelos de consumismo, apelan al deseo de las personas por llenar huecos emocionales - por ejemplo, de autoestima- que son derivados de la moda y el contexto sociocultural.

La clasificación más común de las necesidades de las personas la propuso Abraham Maslow en 1943, una pirámide de cinco niveles, donde el nivel base de la pirámide habla de satisfacción de necesidades fisiológicas, subiendo hasta terminar en la punta con necesidades de autorrealización, que son de índole emocional. 


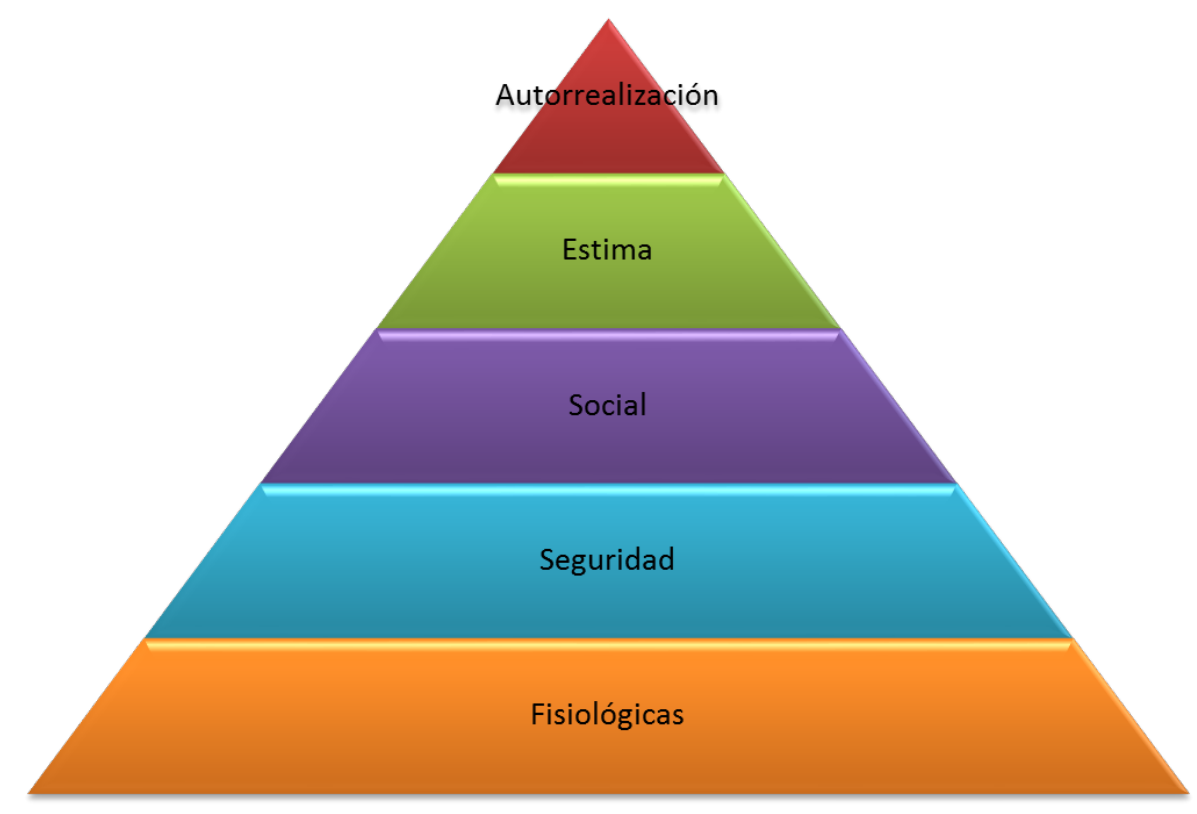

Figura 1. La pirámide de las necesidades.

Fuente: Maslow (1943).

Dicho modelo ha sido usado en el diseño para justificar un paradigma de diseño motivado por el consumismo (Bhamra \& Lofthouse, 2007). A través de él, desde un punto de vista mercadológico, se considera que el consumo resuelve necesidades, dependientes del mercado y no de la persona. Es decir, se busca crear necesidades no existentes para fundamentarlas desde la pirámide de Maslow. En particular en los niveles de necesidades sociales, estima y autorrealización; en lugar solucionar necesidades reales. Se puede argumentar que algunos avances tecnológicos son derivados de crear necesidades, como sería el caso del automóvil o de los celulares, pero en realidad estos avances responden a la búsqueda de hacer más eficientes las alternativas existentes. En el caso del automóvil, de transportación personal; en el caso del celular, de comunicación más efectiva. En cierto modo, una función más eficiente mejora la calidad de vida. Sin embargo, se ha utilizado este tipo de productos para generar modelos de consumo aspiracional, de búsqueda de estilos de vida más que de calidad de vida.

\section{Se puede argumentar que algunos avances tecnológicas son deriy ados de crear neces idades, \\ COMO SERIA EL CASO DEL AUTOMÓVIL O DE LOS CELULARES, \\ PERO EN REALIDAD ESTOS ANANCES RESPONDEN A LA BÚSOUJEDA \\ de hacer más efíientes las aliemaivias existenies.}

Se ha buscado desarrollar nuevos modelos que expliquen la necesidad en sus diferentes facetas y niveles. Esto a su vez, provea a los diseñadores de un nuevo enfoque para el diseño de productos. Uno de los más completos, que explica más detalladamente la interacción entre necesidades físicas y las emocionales, es el de Max-Neef (1992), dicho modelo propone nueve necesidades fundamentales: Subsistencia, Protección, Afecto, 
Entendimiento, Participación, Entretenimiento, Creación, Identidad y Libertad.

Tabla 1. Satisfactores de las necesidades.

\begin{tabular}{|c|c|c|c|c|}
\hline $\begin{array}{l}\text { Necesidades } \\
\text { humanas } \\
\text { fundamentales }\end{array}$ & $\begin{array}{l}\text { Ser } \\
\text { (cualidades) }\end{array}$ & Tener (cosas) & $\begin{array}{l}\text { Hacer } \\
\text { (acciones) }\end{array}$ & $\begin{array}{l}\text { Interacciones } \\
\text { (lugares) }\end{array}$ \\
\hline Subsistencia & $\begin{array}{l}\text { Salud física y } \\
\text { mental }\end{array}$ & $\begin{array}{l}\text { Comida, techo, } \\
\text { trabajo }\end{array}$ & $\begin{array}{l}\text { Alimentación, } \\
\text { vestido, } \\
\text { descanso, } \\
\text { trabajo }\end{array}$ & $\begin{array}{l}\text { Vivienda, } \\
\text { ambiente, } \\
\text { lugares de } \\
\text { convivencia } \\
\text { social }\end{array}$ \\
\hline Protección & $\begin{array}{l}\text { Cuidado, } \\
\text { adaptabilidad, } \\
\text { autonomía }\end{array}$ & $\begin{array}{l}\text { Seguridad social, } \\
\text { Sistemas de salud, } \\
\text { trabajo }\end{array}$ & $\begin{array}{l}\text { Cooperación, } \\
\text { planeación, } \\
\text { hacerse cargo, } \\
\text { ayuda }\end{array}$ & $\begin{array}{l}\text { Ambiente } \\
\text { social, } \\
\text { habitar un } \\
\text { lugar }\end{array}$ \\
\hline Afecto & $\begin{array}{l}\text { Respeto, } \\
\text { sentido del } \\
\text { humor, } \\
\text { generosidad, } \\
\text { sensualidad }\end{array}$ & $\begin{array}{l}\text { Amistad, familia, } \\
\text { relaciones con la } \\
\text { naturaleza }\end{array}$ & $\begin{array}{l}\text { Compartir, } \\
\text { cuidar de, } \\
\text { amar, expresar } \\
\text { emociones }\end{array}$ & $\begin{array}{l}\text { Privacidad, } \\
\text { intimidad, } \\
\text { espacios } \\
\text { intimos de } \\
\text { compañía }\end{array}$ \\
\hline Entendimiento & $\begin{array}{l}\text { Capacidad de } \\
\text { crítica, } \\
\text { curiosidad, } \\
\text { intuición }\end{array}$ & $\begin{array}{l}\text { Literatura, } \\
\text { maestros, } \\
\text { educación }\end{array}$ & $\begin{array}{l}\text { Análisis, } \\
\text { estudio, } \\
\text { investigación, } \\
\text { meditación }\end{array}$ & $\begin{array}{l}\text { Escuela, } \\
\text { familias, } \\
\text { universidades, } \\
\text { comunidades }\end{array}$ \\
\hline Participación & $\begin{array}{l}\text { Receptividad, } \\
\text { dedicación, } \\
\text { sentido del } \\
\text { humor }\end{array}$ & $\begin{array}{l}\text { Responsabilidades, } \\
\text { deberes, trabajo, } \\
\text { derechos }\end{array}$ & $\begin{array}{l}\text { Cooperación, } \\
\text { disentir, } \\
\text { expresar } \\
\text { opiniones }\end{array}$ & $\begin{array}{l}\text { Asociaciones, } \\
\text { fiestas, } \\
\text { iglesias, } \\
\text { vecindarios }\end{array}$ \\
\hline Entretenimiento, & $\begin{array}{l}\text { Imaginación, } \\
\text { tranquilidad, } \\
\text { espontaneidad }\end{array}$ & $\begin{array}{l}\text { Juegos, fiestas, } \\
\text { paz mental }\end{array}$ & $\begin{array}{l}\text { Soñar } \\
\text { despierto } \\
\text { remembranzas, } \\
\text { relajación, } \\
\text { diversión }\end{array}$ & $\begin{array}{l}\text { Paisajes, } \\
\text { espacios } \\
\text { personales, } \\
\text { lugares para } \\
\text { estar solo }\end{array}$ \\
\hline Creación, & $\begin{array}{l}\text { Imaginación, } \\
\text { audacia, } \\
\text { inventiva, } \\
\text { curiosidad }\end{array}$ & $\begin{array}{l}\text { Habilidades y } \\
\text { aptitudes, trabajo } \\
\text { y técnicas }\end{array}$ & $\begin{array}{l}\text { Inventar, } \\
\text { construir, } \\
\text { diseñar, } \\
\text { trabajar, } \\
\text { componer, } \\
\text { interpretar }\end{array}$ & $\begin{array}{l}\text { Espacios de } \\
\text { expresión, } \\
\text { talleres, } \\
\text { audiencias }\end{array}$ \\
\hline Identidad & $\begin{array}{l}\text { Sentido de } \\
\text { pertenencia, } \\
\text { autoestima, } \\
\text { consistencia }\end{array}$ & $\begin{array}{l}\text { Lenguaje, } \\
\text { religiones, } \\
\text { profesiones, } \\
\text { costumbres, } \\
\text { valores, normas }\end{array}$ & $\begin{array}{l}\text { Conocerse a sí } \\
\text { mismo, crecer, } \\
\text { comprometerse }\end{array}$ & $\begin{array}{l}\text { Lugares a los } \\
\text { que } \\
\text { perteneces y } \\
\text { lugares } \\
\text { diarias }\end{array}$ \\
\hline Libertad. & $\begin{array}{l}\text { Autonomía, } \\
\text { pasión, } \\
\text { autoestima, } \\
\text { mente abierta }\end{array}$ & $\begin{array}{l}\text { Igualdad de } \\
\text { derechos, }\end{array}$ & $\begin{array}{l}\text { Disentir, } \\
\text { escoger, correr } \\
\text { riesgos, } \\
\text { desarrollar } \\
\text { conciencia }\end{array}$ & $\begin{array}{l}\text { Cualquier } \\
\text { lugar }\end{array}$ \\
\hline
\end{tabular}

Fuente: Max-Neef (1992).

Dichas necesidades están relacionadas con cuatro estados de existencia: ser, tener, hacer e interactuar. En su argumento, las necesidades básicas permanecen igual a lo largo del tiempo y las culturas, pero lo que cambia es la forma en que se satisfacen los objetos que le permiten a la persona llevar a cabo esto. Concluye con que sólo dos de estas necesidades requieren satisfactores naturales, pero la actual sociedad ha generado una cultura objetual que busca satisfacer todas a través del consumo de objetos a modo de recompensa emocional (Max-Neef, 1992). 
Por ejemplo, a modo de análisis: existe una necesidad de pertenencia y de autoestima se relaciona al contexto del ser. Estas son impactadas por el contexto de la interacción. La persona genera un sentido de pertenencia y de valor de sí mismo influenciado por la forma en que interactúa en grupo o con el medio. Una situación de discriminación impacta de manera negativa en la aceptación de la persona para con su grupo social, en detrimento de su sentimiento de pertenencia y autoestima, perjudica su capacidad para obtener otros satisfactores básicos, como techo o alimento. Asimismo, enlista la necesidad de libertad como algo que proviene de la autoestima. Esta necesidad de libertad se manifiesta en un deseo por la equidad de derechos que se confronta con actitudes subversivas en donde la realidad es que las mismas comunidades pueden presentar comportamientos discriminatorios que coartan la consecución de estas necesidades (Starmans et al., 2017).

En términos de diseño, no hay mejor ejemplo que el teléfono móvil, objeto que responde a una necesidad real, mantenerse comunicado. Antes de su creación, las llamadas telefónicas dependían de que se tuviera un acceso en un punto fijo y si se usaba un teléfono de la calle, no era posible recibir llamadas, por lo tanto, localizar a alguien que se hallaba en movimiento era complicado. Con los teléfonos móviles esta limitación desapareció. Pero al mismo tiempo, desapareció gran parte de la privacidad de las llamadas fijas; pues la gente ahora se comunica en áreas públicas sin importarle quién pueda oír. Conforme nuevas innovaciones se le agregaron al teléfono móvil, pasamos de llamar a mandar mensajes de texto, al uso de redes sociales para comunicarnos, reduciendo (a veces por costo) el uso de llamadas de viva voz.

Pero al mismo tiempo, el teléfono móvil se ha vuelto satisfactor de una necesidad de identidad. Aunque la mayoría de los sistemas operativos de los 'smartphones' tienen funciones similares, muy a menudo, son elegidos en función de la marca. Esto explica por qué hay modelos básicos que están a precios accesibles que las mismas compañías telefónicas regalan y equipos que cuestan casi diez veces lo de los otros. Adicionalmente, cada cierto tiempo, los fabricantes de los celulares lanzan nuevos modelos con ligeras mejoras, mientras fuerzan una obsolescencia programada a través de la eliminación de actualizaciones para los sistemas operativos. De esta manera conducen al consumidor a comprar celulares nuevos cada cierto tiempo, ya sea porque se les hace percibir que su equipo es obsoleto o porque no están 'a la moda'. En realidad, los celulares 'obsoletos' pueden seguir cumpliendo la necesidad real, que es la de permitir comunicación independientemente de la locación. Son todas las necesidades 'aledañas' o creadas alrededor del producto, no de la necesidad real, que hacen que se consuman más celulares aún cuando no son del todo necesarios.

Desmet (2010) expone un modelo que explica cómo son evaluados por el consumidor los objetos en tres posibles niveles:

- Evaluación de la utilidad: la relación de un producto con respecto a las metas de la persona.

- Evaluación de placer: el atractivo sensorial de los productos, que tanto produce placer o dolor. 
- Evaluación de rectitud: que tanto el objeto cumple una serie de estándares o expectativas, usualmente derivados de las creencias personales y las convenciones sociales que influyen en el pensamiento.

Entender estas diferencias sobre cómo y a qué nivel se generan las necesidades, nos pueden ayudar a llevar al diseño de un modelo motivado por el consumo, a un modelo motivado por necesidades reales. Sin embargo, este cambio requiere también modificar a nivel estratégico y operacional, cómo se aborda el diseño. En particular, el uso de elementos estéticos para despertar emociones determinadas entre los consumidores. También es necesario saber cómo la manipulación de las emociones apela a las necesidades psicológicas para vender productos.

\section{Entender estas diferencias \\ SOBRE CÓMO Y A QUÉ NIVEL SE GENERAN LAS NECESIDADES, NOS PUEDENAYIDARA LLEVAR AL DISEÑO DE INHDDELO MDTIWADO PREL OONSLHO, \\ a un modelo motivado por necesidades reales.}

\section{LA MANIPULACIÓN DE LAS NECESIDADES A TRAVÉS DE ESTRATEGIAS EMOCIONALES}

Retomando los modelos de necesidad mencionados, se puede observar que existe una necesidad, la cual depende en gran medida de la adquisición de ciertos objetos: La necesidad de generar una identidad, la cual se ve re flejada en los objetos adquiridos. No sólo por su función, sino también por el tipo de emociones que provocan en las personas a través de su estética. Estas emociones atacan nuestra mente en diversos niveles, pero no siempre somos conscientes de eso. En muchos casos, se genera un apego a dichos objetos.

Los cambios acelerados y repentinos que sufre el mundo constantemente, generan ansiedad, incertidumbre y temor entre las personas, por lo que éstas buscan recuperar el control o generar sensaciones calmantes y positivas, a través de acciones como adoptar rituales, apegarnos a rutinas y a apelar a la memoria (Lindstrom, 2008). El diseño tiene un impacto social considerable, en tanto muchos de los productos que se crean y desarrollan, establecen o fomentan determinados estilos de vida que a su vez afectan el bienestar físico y emocional de las personas: en detrimento de ellas y del ambiente. Un ejemplo son las revueltas de Londres de 2011, cuando uno de los principales factores para el saqueo de comercios fue una cuestión de consumismo desmedido de gente deseosa de tener los objetos de moda que normalmente no puede adquirir, pero que ansiaba poseer el estilo de vida eran promovidos por la mercadotecnia.

Como resultado, se impulsa el consumismo indiscriminado en el ser humano, al cual sólo se le valora o se le da una identidad por su capacidad de adquirir bienes y por el dinero en su cartera. Genera una visión perversa de la búsqueda de la "felicidad". Una forma en que la identidad de la 
persona se moldea a través de las marcas que usa, su etiqueta social le permite ser incluido en un grupo social-cultural determinado.

\section{REINTERPRETANDO LAS NECESIDADES DESDE UN ENFOQUE SUSTENTABLE}

Jonathan Chapman y Nick Gant (2007) cuestionan la existencia de algo que sea 100 por ciento sustentable. Este por ciento es equiparado a una utopía. Otra forma de interpretar este 100 por ciento sería verlo como un idea, puesto que la diferencia entre un ideal y una utopía es que la utopía no es alcanzable, sólo un parámetro de comparación de cómo deberían ser las cosas, mientras que un ideal, aunque también difícil de alcanzar, existe como inspiración para la mejora e innovación, aunque sea de manera paulatina hasta que sea factible dar soluciones de diseño que, si bien, no sean 100 por ciento sustentables, si se aproximen lo más posible.

En este sentido, es menester entender que sustentabilidad no se refiere exclusivamente a la parte ambiental . El componente social de la sustentabilidad tiene un peso considerable, porque si una sociedad no se encuentra bien, es difícil que se genere la voluntad y la consciencia requeridas para la protección ambiental. Coexisten en una especie de simbiosis . Por tanto, el diseño que aspire a ser sustentable debe considerar los impactos sociales de los productos que desarrolla. Y la mayor fuente de los impactos sociales se encuentra en qué necesidades se satisfacen y cómo se hace.

Como se mencionó, las personas adquieren los objetos para satisfacer alguna necesidad, pero qué versión de dicho objeto adquieren es influenciado por las emociones que estos les generan. Estas emociones impactan en uno de los cuatro estados propuestos por Max-Neef (ser, tener, hacer e interactuar), que se combinan con los cuatro niveles propuestos por Desmet.

Se genera la siguiente tabla: 
Tabla 2. Modelo que combina los estados del ser descritos por Max Neef con los niveles de evaluación de un producto propuestos por Desmet.

\begin{tabular}{|c|c|c|c|c|}
\hline $\begin{array}{l}\text { Niveles de } \\
\text { evaluación } \\
\text { vs. Estados } \\
\text { del ser }\end{array}$ & Ser & Tener & Hacer & Interactuar \\
\hline Utilidad & $\begin{array}{l}\text { Su existencia atienda } \\
\text { a una necesidad real } \\
\text { existente }\end{array}$ & $\begin{array}{l}\text { El tener el } \\
\text { objeto da al } \\
\text { usuario la } \\
\text { posibilidad se } \\
\text { satisfacer una } \\
\text { necesidad }\end{array}$ & $\begin{array}{l}\text { Su uso } \\
\text { soluciona un } \\
\text { problema }\end{array}$ & $\begin{array}{l}\text { Generación de } \\
\text { conexiones } \\
\text { personales entre } \\
\text { usuarios }\end{array}$ \\
\hline Placer & $\begin{array}{l}\text { El objeto genera un } \\
\text { sentido de } \\
\text { pertenencia y lo } \\
\text { identidad }\end{array}$ & $\begin{array}{l}\text { El tener el } \\
\text { objeto } \\
\text { complace } \\
\text { sensorialmente } \\
\text { al usuario }\end{array}$ & $\begin{array}{l}\text { Estéticamente } \\
\text { el objeto } \\
\text { genera } \\
\text { emociones } \\
\text { positivas en el } \\
\text { usuario }\end{array}$ & $\begin{array}{l}\text { Está configurado de } \\
\text { tal manera que la } \\
\text { interacción con el } \\
\text { usuario es } \\
\text { divertida/relajante/sin } \\
\text { complicaciones }\end{array}$ \\
\hline Rectitud & $\begin{array}{l}\text { El objeto es } \\
\text { congruente con los } \\
\text { valores internos del } \\
\text { usuario }\end{array}$ & $\begin{array}{l}\text { El objeto le } \\
\text { permite al } \\
\text { usuario ser } \\
\text { congruente con } \\
\text { sus valores }\end{array}$ & $\begin{array}{l}\text { El objeto } \\
\text { permite al } \\
\text { usuario a } \\
\text { mejorar su } \\
\text { calidad de vida }\end{array}$ & $\begin{array}{l}\text { El objeto es } \\
\text { congruente con los } \\
\text { valores sociales y lo } \\
\text { los fomenta para con } \\
\text { otros (respeto, } \\
\text { tolerancia, } \\
\text { integración) }\end{array}$ \\
\hline
\end{tabular}

Fuente: Elaboración propia.

Un ejemplo de un producto que cumple con este nuevo marco es la primera minifigura de Lego (figura 2), que representa una discapacidad, en este caso la paraplejia. Su creación ha generado a Lego una ola de felicitaciones por parte de padres de familia, coleccionistas y grupos defensores de las personas con discapacidad, pues provee de representatividad a más de 150 millones de niños alrededor del mundo que padecen alguna discapacidad y que están empezando a ser presentados de manera positiva en los juguetes que consumen (Atkinson, 2016). 


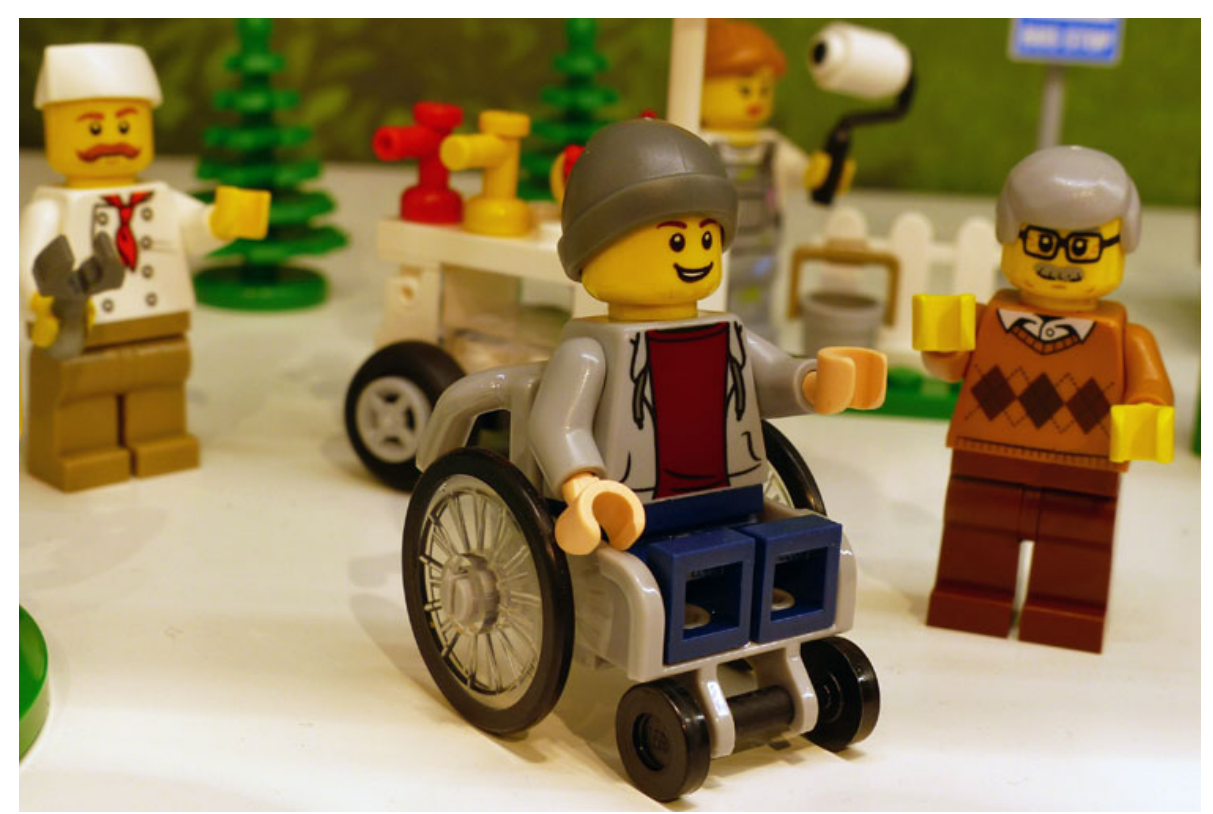

Figura 2. Minifig en silla de ruedas.

Fuente: Friedrichs (2016).

Aplicando la tabla 2 a este producto, es factible realizar un análisis para argumentar si cumple o no con esta redefinición de la necesidad. Hay que aclarar que para efectos de este ejercicio, no se está evaluando el precio del objeto, si no solamente como desde el punto de vista de necesidad y de estado emocional cumple o no con el objetivo para el cual se le planteó: 
Tabla 3. Análisis de la minifigura de Lego en silla de ruedas.

\begin{tabular}{|c|c|c|c|c|}
\hline $\begin{array}{l}\text { Niveles de } \\
\text { evaluación } \\
\text { vs. } \\
\text { Estados } \\
\text { del ser }\end{array}$ & Ser & Tener & Hacer & Interactuar \\
\hline Utilidad & $\begin{array}{l}\text { Atiende a dos } \\
\text { necesidades: } \\
\text { identidad y juego }\end{array}$ & $\begin{array}{l}\text { Su existencia } \\
\text { resuelve una } \\
\text { necesidad de } \\
\text { identificación }\end{array}$ & $\begin{array}{l}\text { Soluciona el } \\
\text { problema de } \\
\text { mayor } \\
\text { representatividad } \\
\text { y coadyuva a la } \\
\text { actividad del } \\
\text { juego creativo } \\
\text { entre infantes }\end{array}$ & $\begin{array}{l}\text { Elimina la } \\
\text { barrera } \\
\text { psicológica que } \\
\text { hay entre } \\
\text { personas con } \\
\text { discapacidad y } \\
\text { las que no la } \\
\text { tienen, al } \\
\text { normalizar la } \\
\text { presencia de } \\
\text { personas con } \\
\text { discapacidad } \\
\text { en un juego } \\
\text { que fomenta la } \\
\text { imaginación y } \\
\text { el desarrollo } \\
\text { creativo del } \\
\text { usuario }\end{array}$ \\
\hline Placer & $\begin{array}{l}\text { Permite generar } \\
\text { un sentido de } \\
\text { pertenencia e } \\
\text { identidad entre los } \\
\text { niños } \\
\text { parapléjicos, pues } \\
\text { los representa en } \\
\text { lugar de } \\
\text { segregarlos }\end{array}$ & $\begin{array}{l}\text { Los Legos son de } \\
\text { por sí agradables } \\
\text { a la vista. La silla } \\
\text { de ruedas tiene } \\
\text { componentes } \\
\text { estéticos } \\
\text { placenteros (pero } \\
\text { se puede mejorar) }\end{array}$ & $\begin{array}{l}\text { Los Legos } \\
\text { permiten a los } \\
\text { usuarios con } \\
\text { discapacidad, } \\
\text { sentiré } \\
\text { integradose } \\
\text { identificados en } \\
\text { este artículo } \\
\text { para el juego }\end{array}$ & $\begin{array}{l}\text { Permite a los } \\
\text { usuarios } \\
\text { nuevas } \\
\text { posibilidades } \\
\text { de diversión e } \\
\text { integración }\end{array}$ \\
\hline Rectitud & $\begin{array}{l}\text { Padres de familia, } \\
\text { asociaciones } \\
\text { civiles y los } \\
\text { mismos } \\
\text { coleccionistas de } \\
\text { Lego lo han } \\
\text { aceptado con } \\
\text { gusto por el nivel } \\
\text { de } \\
\text { representatividad } \\
\text { que genera }\end{array}$ & $\begin{array}{l}\text { El Lego en } \\
\text { cuestión ayuda a } \\
\text { mostrar una } \\
\text { mayor diversidad } \\
\text { y } \\
\text { representatividad } \\
\text { a niños con } \\
\text { discapacidad }\end{array}$ & $\begin{array}{l}\text { El Lego en } \\
\text { cuestión ayuda } \\
\text { emocional y } \\
\text { psicológicamente } \\
\text { a usuarios con } \\
\text { discapacidad a } \\
\text { ya no sentirse } \\
\text { excluidos }\end{array}$ & $\begin{array}{l}\text { El objeto es } \\
\text { congruente con } \\
\text { los valores } \\
\text { sociales y lo los } \\
\text { fomenta para } \\
\text { con otros } \\
\text { (respeto, } \\
\text { tolerancia, } \\
\text { integración) }\end{array}$ \\
\hline
\end{tabular}

Fuente: Elaboración propia.

Según la tabla 3, la figura cumple con dos necesidades en particular: la de jugar -que es importante para el desarrollo del niño- y la de identificación, pues presenta una imagen positiva e incluyente. Si bien, se puede debatir la cuestión de qué tan accesible es una figura Lego, el diseño de la misma, que es lo que atiende este artículo, presenta una combinación adecuada de cómo atiende una necesidad de desarrollo psicológico y social, así como emocional del usuario. Lo que hace a este producto socialmente responsable.

Derivado de este ejercicio, se considera es posible proponer que una necesidad de diseño, dentro de un contexto más sustentable y/o socialmente responsable, como una problemática real que afecta el bienestar de una persona en uno o más de los cuatro estados de existencia: 
ser, tener, hacer e interactuar; posee un componente psicológico que impacta positivamente la forma en que busca ser solucionada.

\section{CONCLUSIONES}

Como se aborda en este artículo, la importancia de resolver necesidades a través del diseño es crucial, tanto para el contexto social-cultural como del cuidado del medio ambiente. Satisfacer una necesidad no debe implicar un consumo irresponsable de recursos. Si se espera que el diseño de un producto aspire a ser sustentable y/o socialmente responsable, debe resolver los "estados del ser" del consumidor final, de manera que éste haga una compra informada y no una por 'capricho', que es la que suele generar impactos más negativos. Es imperativo aplicar un análisis metodológico como el modelo que combina los estados del ser descritos por Max Neef con los niveles de evaluación de un producto propuestos por Desmet. La labor creativa del diseño debe ser metodológica y responsable con su entorno, tanto ambiental como social, pues ambos repercuten entre sí. Queda entonces, seguir aplicando esta propuesta de modelo de evaluación en otros productos y propuestas de diseño, para continuar midiendo su efectividad.

\section{Satifacer una recesidad}

NO DEBE IMPLICAR

UW CONSUMO IRRESPONSABLEDERECURSOS.

\section{FUENTES DE CONSULTA}

Atkinson, R. (2016), Lego's plastic wheelchair guy is a seismic shift in a toy box. The Guardian. 1 de febrero de 2016. [En línea] http://www.theguardian.com/commentisfree/2016/feb/01/legowheelchair-toys-message-disabilities, consultado el 16 de febrero de 2016.

Bhamra, T. \& Lofthouse, V. (2007), Design for sustainability: a practical approach, Gower, Londres.

Brundtland, G.H. (1987), Our Common Future: Brundtland Report. Naciones Unidas. [En línea] http://worldinbalance.net/intagreements/1987brundtland.php, consultado el 16 de febrero de 2016.

Chapman, J. \& Gant, N. (2007), Chapter 1 Introduction. En J. Chapman \& N. Gant, (edits.). Designers, Visionaries and Other Stories. A Collection of Sustainable Design Essays. Earthscan, Londres, pp. 2-13.

Desmet, P.M.A. (2010), Three levels of product emotion. International Conference On Kansei Engineering And Emotion Research.

Friedrichs, M. (2016), “Toy Fair 2016: LEGO lanza la primera serie con el niño en silla de ruedas $y$ hace un bebé minifigure". Promobricks. 28 de enero de 2016. [En línea] http://www.promobricks.de/spielwarenmesse-2016-lego-stellt- 
erstes-set-mit-kind-im-rollstuhl-und-baby-minifigur-vor/12673, consultado el 16 de febrero de 2016.

Lindstrom, M. (2008), Compradicición. Verdades y mentiras de porqué las personas compran, Doubleday, Nueva York.

Leonard, A. (2010), The Story of Stuff, Constable, Londres.

Max-Neef, A.M. (1992), 'From the Outside Looking' in Experiences in 'Barefoot Economics', Zed Books, Londres.

Maslow, A.H. (1943), A Theory of Human Motivation. Psychological Review, 50, pp. 370-396. [En línea] http://dx.doi.org/10.1037/h0054346, consultado el 29 de abril de 2019.

Papanek, V. (1985), Design for the Real World, Pantheon Books, New York. 